\title{
ENTRE MUNDOS E ENTRE SABERES: OS DESAFIOS EPISTEMOLÓGICOS DOS ALUNOS AKWEN XERENTE NA UNIVERSIDADE FEDERAL DO TOCANTINS
}

\author{
ReiJane Pinheiro da Silva \\ Universidade Federal do Tocantins (UFT), Palmas, Tocantins, Brasil
}

\begin{abstract}
Resumo: Como parte dos resultados de uma pesquisa realizada com os alunos indígenas da Universidade Federal do Tocantins (UFT) em 2011, apresentamos neste artigo algumas reflexões acerca da forma como os alunos indígenas Akwen Xerente, matriculados na UFT, no câmpus de Miracema, veem os conhecimentos com os quais passam a lidar ao ingressarem na universidade. Apresentamos também como os comparam ao saber da sua sociedade, por eles denominado "tradicional e natural", e como escapam criticamente ao cientificismo ainda persistente em muitos setores da academia. Tendo em vista elementos característicos das formas Akwen de ver e interpretar o mundo, problematizamos a falta de abertura da universidade para a tradição epistemológica por eles representada. Palavras-chave: Alunos indígenas Akwen Xerente. Conhecimento acadêmico. Saberes tradicionais.
\end{abstract}

INTRODUÇÃO

Entre segunda e sexta-feira, às quatro horas da manhã, R. Xerente, 35, um dos três professores da aldeia Porteira, localizada na Terra Indígena Xerente, em Tocantínia, Tocantins (TO), se levanta rapidamente e, sem realizar o desjejum, enfrenta com sua bicicleta os 20 quilômetros que separam sua aldeia do Câmpus da UFT localizado em Miracema, TO. Ao fim 
das aulas, R. Xerente percorre a mesma distância de volta. Além da estrada sujeita a buracos e lamaçais na estação chuvosa, parte do trajeto deve ser realizado de balsa, pois Miracema e Tocantínia se localizam em margens opostas do Rio Tocantins. R. Xerente é aluno do terceiro período do curso de Pedagogia. Como a grande maioria dos alunos indígenas da UFT, ele tem enfrentado um desafio considerado fundamental para que os Povos indígenas ${ }^{1}$ no Brasil assumam definitivamente o lugar de agentes dos seus direitos na relação com o Estado e com a sociedade brasileira: obter um diploma de ensino superior.

Diante da experiência de alunos indígenas como ele e considerando a complexidade da relação já duradoura entre os Povos Indígenas e a sociedade envolvente no Brasil, apresentamos neste artigo algumas reflexões acerca das impressões dos alunos indígenas Akwen Xerente matriculados na UFT. Reflexões sobre aspectos dos conhecimentos com os quais passam a lidar ao ingressarem na Universidade, como os comparam ao saber da sua sociedade, por eles denominado de "tradicional e natural", e como escapam criticamente ao cientificismo ainda persistente em muitos setores da academia. Este artigo é parte dos resultados de uma pesquisa realizada em 2011 com os alunos indígenas da UFT, cujo objetivo foi identificar aspectos do contato dos cotistas indígenas com o ambiente acadêmico e privilegia o olhar desses alunos sobre o tema.

No Tocantins vivem nove Povos Indígenas ${ }^{2}$ : os Akwen-Xerente, Mehin-Krahô, Pahin-Apinajé, Iny-Javaé-Karajá-Xambioá, os Krahó-Kanela, Avá Canoeiro e Guarani ${ }^{3}$. Todos eles, a despeito das representações dominantes, se constituem como fundamentalmente singulares. Suas perspectivas cosmológicas e sua organização social diferem significativamente. Matriculados na UFT, temos alunos de quase todos esses povos, com exceção dos Avá Canoeiro e Guarani. Em menor número estão os Mehin-Krahô e em maior os Akwen-Xerente. Convém ressaltar que, apesar da diversidade indígena presente na UFT, este texto se sustenta na interlocução com os alunos indígenas Akwen-Xerente, dada a proximidade como o universo em questão, alcançada em trabalhos anteriores (SILVA, 2010; 2011; 2013). 


\section{UFT E AS "COTAS" PARA INDÍGENAS}

Em 2004 a UFT passou a reservar 5\% das vagas oferecidas nos cursos de graduação a estudantes indígenas. As provas do concurso vestibular são as mesmas aplicadas aos alunos do sistema universal, no entanto os indígenas concorrem entre si. No ano de 2011 haviam alunos Akwen Xerente matriculados nos seguintes cursos: Jornalismo, Pedagogia, Serviço Social, Zootecnia, Ciências Contábeis, Engenharia Ambiental, Administração, Direito, Agronomia, Enfermagem, Nutrição, Medicina Veterinária e História ${ }^{4}$. O anseio pelo ingresso no ensino superior é partilhado por boa parte dos jovens Akwen, visto como um dos caminhos para garantir a inserção no mercado de trabalho diante dos desafios de sobrevivência que se apresentam para eles e para todo o povo (BRITO, 2013).

No que se refere ao registro sobre a diversidade indígena na UFT, convém ressaltar que a Pró-Reitoria de Graduação da UFT (PROGRAD) usa apenas a categoria "indígena" para identificá-los, o que indica a reprodução da perspectiva generalista que predomina nas representações sobre esses povos no Brasil. Segundo a Diretoria de Registro acadêmico (DIRCA), a seleção de 2016 já contará com a identificação do pertencimento.

PRESENÇA INDÍGENA NA UFT - PERÍODO 2008 A 2015

\begin{tabular}{ccc}
\hline INGRESSO & DESISTÊNCIAS-DESVINCULADOS- CANCELAMENTOS & CONCLUÍRAM \\
\hline 437 & 121 & 30 \\
\hline
\end{tabular}

Fonte: Pró-Reitoria de Graduação- UFT

A reserva de vagas para a UFT não foi acompanhada de uma discussão que considerasse o significado da presença indígena na universidade e também não houve um planejamento de ações voltadas para "a permanência" e o "sucesso" desses alunos, princípio importante das políticas de ação afirmativa. A falta de uma reflexão sobre quem são os alunos indígenas que ingressam pode ser constatada na ausência da identidade desses alunos, subsumidos na categoria "Indígena", como apontamos no quadro acima. Apenas três anos depois do ingresso dos primeiros cotistas, a universidade criou dois programas com o objetivo de acompanhar estes alunos: o Grupo 
de Trabalho Indígena (GTI) e o Programa Institucional de Monitoria Indígena (PIMI). Ambos permanecem ativos, mas precisam ser repensados e reestruturados, pois se mostram insuficientes no universo de complexidades que estes alunos enfrentam na universidade. Segundo Carvalho (2010), que analisou a permanência dos alunos indígenas na UFT durante os dez anos da implantação das "cotas", esse é o principal desafio da UFT no que se refere à consolidação dessa política.

Antes da implantação do Plano Nacional de Assistência Estudantil (PNAES), em 2007, o acompanhamento dos alunos e a oferta de bolsas foram viabilizados por meio de projetos de extensão, pelo Núcleo de Estudos em Assuntos Indígenas da UFT (NEAl), e pela Rede de Educação, ligada aos pesquisadores desse grupo. Com as possibilidades apresentadas pelo PNAES, a UFT passou a contar com recurso específico para a assistência a estudantes em situação de vulnerabilidade econômica. Pelo PNAES, o Programa Bolsa Permanência (PBP) garantiu a todos os alunos que atendiam aos critérios o auxílio mensal de 400 reais, já os alunos indígenas passaram a receber 900 reais. Segundo a Comissão Própria de Avaliação (CPA) da UFT, que analisou aspectos da assistência estudantil na instituição, os alunos indígenas se destacam em evasão e o "baixo rendimento", além de, assim como os outros alunos, não contarem com restaurante universitário ${ }^{5}$ e viverem em condições precárias nas casas de estudantes de Palmas:

[...] A situação precária das casas dos estudantes, a falta de RUs e de transporte público mostram as fragilidades e sinalizam para além da distribuição de bolsas assistencialistas e para a necessidade de políticas efetivas de assistência. Também, outro aspecto a ser aprimorado na UFT diz respeito ao atendimento aos alunos e à permanência deles na instituição. A instituição precisa discutir e implementar medidas visando ao enfrentamento da questão, tais como: atendimento psicopedagógico e social por equipes especializadas, multidisciplinar (psicólogo, pedagogo e assistente social) e programas de nivelamento para superar as dificuldades de leitura e escrita, principalmente aos alunos indígenas, que representam um número significado dentro da Universidade e que, na maioria dos casos, apresentam baixo rendimento e alta evasão. (UFT, 2013, p. 195).

Além das dificuldades econômicas e das novas necessidades que a inserção na universidade impõe aos alunos indígenas, é freqüente o 
relato de situações constrangedoras em sala de aula e em outros espaços da universidade (SILVA, 2011). A dificuldade com a língua portuguesa, por exemplo, é confundida com déficit cognitivo, tanto por parte dos colegas como de professores. Convém ressaltar que entre os Povos citados, apenas os Krahô-Canela tem o português como primeira língua, todos os outros só aprendem português quando ingressam na escola, em torno de seis ou sete anos. Como é possível constatar também entre os não índios, nem sempre o ensino regular consegue contribuir para que esses alunos dominem completamente a escrita da segunda língua, dificuldade evidenciada quando eles chegam ao ensino superior. $O$ fato de que a escrita é uma possibilidade muito recente entre os Akwen e outros povos indígenas, nos chama a atenção para as dificuldades de sujeitos que pertencem a uma tradição oral terem de se apropriar de saberes que circulam e se consolidam pela escrita.

Toda essa realidade é sintomática de um processo que ignorou a complexidade e as possibilidades da inserção de estudantes indígenas na UFT. Como é possível constatar, nem as condições objetivas necessárias foram preparadas: alimentação, transporte para deslocamento, bolsas, moradia, adaptação, etc. $\mathrm{O}$ que discutimos a seguir problematiza outro aspecto da inserção desses alunos na academia, quais sejam as profundas diferenças epistemológicas entre a nossa perspectiva e forma de entender e explicar o mundo, com as formas próprias dos povos com os quais convivemos no Tocantins.

\section{OS INDÍGENAS NA UNIVERSIDADE}

A presença indígena na universidade deve ser situada no contexto das significativas transformações que ocorreram nas relações dos povos indígenas do Brasil com a sociedade e o Estado brasileiro, nos últimos vinte anos. Os caminhos que levaram às garantias do direito de preservação da sua cultura, além da demarcação das suas terras, envolveram um denso debate entre os que defendiam um projeto integracionista e os defensores dos direitos tradicionais desses povos à sua identidade cultural. A defesa dos direitos indígenas como originários, ou seja, anteriores à própria constituição da Nação, chocou-se com a uma proposta de lei que emancipava os chamado índios aculturados, 
dez anos antes da promulgação da constituição. Essa proposta se tornou um marco para a mobilização do movimento indígena e de entidades da sociedade civil, marcando a fase contemporânea do ativismo indígena (RAMOS, 2004).

Em síntese "emancipar" significava, segundo Cunha (2009), revogar o direito de esses sujeitos serem legalmente índios e consequentemente o direito às terras que tradicionalmente ocupavam. A mobilização de entidades de defesa dos povos indígenas, de lideranças indígenas e da Associação Brasileira de Antropologia (ABA), contra a emancipação, promoveu uma forte articulação e debates em torno das garantias dos direitos indígenas cujo sucesso pode ser atestado no artigo 231 da Constituição Federal, que trata do direito inalienável dos povos indígenas às suas terras e identidade étnica, apresentado no capítulo VIII (BRASIL, 1988):"São reconhecidos aos índios sua organização social, costumes, línguas, crenças e tradições, e os direitos originários sobre as terras que tradicionalmente ocupam, competindo à União demarcá-las, proteger e fazer respeitar todos os seus bens".

Os primeiros dez anos após a promulgação da Constituição de 1988 foram muito importantes para o crescimento demográfico dos povos indígenas no Brasil, até então vivendo à sombra das teses que afirmavam sobre o seu desaparecimento eminente. Políticas públicas de educação e saúde, principalmente o controle vacinal e o acompanhamento às gestantes, garantiram um crescimento demográfico de $150 \%$ da população indígena brasileira entre a década de 1990 e 2010, segundo o censo do IBGE (2010). Os últimos dez anos foram marcados, no entanto, por retrocessos políticos, caracterizados por manifestações dos que defendem a flexibilização do direito indígena a terra e a retomada do velho tema da integração. A Proposta de Emenda à Constituição 215 (PEC 215) propõe, por exemplo, que a demarcação de terras deixe de ser função do executivo e passe a ser de responsabilidade do parlamento. A Fundação Nacional do Índio (FUNAI) perderia a prerrogativa de reconhecer e demarcar as terras tradicionalmente ocupadas pelos Povos Indígenas no Brasil, atribuição que seria dada aos representantes legislativos, muitas vezes aliados aos interesses dos grandes grupos econômicos e do agronegócio.

No que se refere ao contexto histórico e político das relações entre os povos indígenas e a sociedade envolvente no Tocantins, é importante consi- 
derar que entre os argumentos apresentados pelo movimento autonomista, que defendeu e articulou a criação do estado, estavam as profundas diferenças econômicas e identitárias que marcavam as regiões norte e sul de Goiás. Os defensores da criação do Tocantins, a partir da divisão de Goiás, sugeriam que o atraso da antiga região norte do estado estava estreitamente vinculado às populações que a ocupavam: indígenas, sertanejos e negros, e também ao abandono por parte da administração centralizada na região sul do estado. O que se esperava com a autonomia é que essa região fosse totalizada pela nação. Para isso, precisaria ser "desinfectada" dos seus habitantes originais. Entre as tentativas de acelerar o extermínio dos povos indígenas do norte de Goiás, por exemplo, estão a contaminação proposital por bexiga e o envenenamento das águas com estricnina (RIBEIRO, 1995).

Como apresenta Mellati (1967), em pesquisa sobre o povo Krahô na década de 1960, a representação dos indígenas na sociedade regional continuava marcada pela violência e pelo preconceito, sem dúvida resultado dos embates sistemáticos entre estes e os criadores de gado, que seguiram os desbravadores bandeirantes e mineiros ao longo do século XVII, invadindo, paulatinamente, as terras já ocupadas pelos povos indígenas. $O$ autor apresenta que, em síntese, os indígenas eram vistos como preguiçosos e propensos ao furto, sujos e ignorantes. Em Tocantínia, TO, (SILVA, 2010), atestamos que esses estigmas permanecem e a eles somam-se as ideias do indígena que "gosta muito de dinheiro e de pinga".

Essas representações extremamente negativas, constituídas historicamente, continuam intermediando as relações entre os povos indígenas do Tocantins e a sociedade não indígena, como atestamos na pesquisa indicada. Constatamos, ainda, que mesmo no âmbito das políticas públicas a visão colonizadora e etnocêntrica permanece, ainda que de forma sutil, como orientação de atuação juntos aos povos em questão.

\section{O TRÂNSITO ENTRE SABERES}

As reflexões aqui apresentadas se deparam com elementos de duas perspectivas associadas à produção do saber. A da ciência, com suas origens 
no racionalismo empiricista cartesiano e a perspectiva Akwen Xerente, que se sustenta em representações da totalidade entre os seres vivos, cujas relações são concebidas como simétricas e equânimes (MAYBURY-LEWIS, 1979). Dessa forma uma questão que de imediato se apresenta é como os alunos indígenas interpretam esse trânsito entre fronteiras de conhecimento e se hierarquizam as possibilidades dos saberes em questão. A comparação entre esses conhecimentos, ou entre essas ciências, sempre se pautou pela tese da irracionalidade e pelo foco nos resultados, conforme as considerações de Cunha (2009). Nessa perspectiva, o conhecimento indígena e outras formas de conhecimento tradicional foram subestimados e muitas vezes interpretados como respostas às necessidades de sobrevivência, considerados "pré-lógicos", conceito amplamente utilizado para inúmeras classificações referentes aos saberes ou crenças dos povos indígenas, bem como de todas as que estavam alheias ao escopo geográfico e epistemológico da ciência moderna ${ }^{6}$.

A antropologia sempre foi desafiada a pensar essas perspectivas a partir da ótica nativa, das categorias êmicas, pois se constituiu como ciência no contato com a diferença. Entre outras, as contribuições revolucionárias de Lévi-Strauss (1989) e do trabalho clássico de Evans-Pritchard (2005), trouxeram para o debate acadêmico elementos que mostram que a observação, o rigor, a lógica e a sistematização não são exclusividade da ciência moderna ocidental.

Diferente da forma de conhecer que marca a abordagem das populações ameríndias sobre o mundo, a condição fundamental para o estabelecimento de um paradigma como o da Ciência Moderna está no distanciamento homem/natureza, cultura/natureza. Sem essa postura, a relação primordial entre o que se convencionou chamar de sujeito (homem/cultura) e objeto (natureza), não seria possível. Resultado da Revolução científica do século XVI, a ciência moderna tem uma faceta totalitária, pois negou o caráter racional a todas as outras formas de saber que não partilhavam dos seus referentes epistemológicos. O lugar de verdade que pretende, ancora-se na crença de que a pesquisa empírica é superior às narrativas orais, imagens, mitologias ou outras formas de testemunhos. Segundo Cunha (2009, p. 301), as diferenças entre os conhecimentos em questão devem ser consideradas para além de resultados, pois se encontram em níveis mais profundos: 
Poderíamos começar notando que, de certa maneira, os conhecimentos tradicionais estão para o científico como religiões locais para as universais. O conhecimento científico se afirma, por definição, como verdade absoluta, até que outro paradigma o venha sobrepujar, como mostrou Thomas Kuhn. Essa universalidade do conhecimento científico não se aplica aos saberes tradicionais, muito mais tolerantes, que acolhem freqüentemente com igual confiança ou ceticismo explicações divergentes, cuja validade entendem seja puramente local.

Os conhecimentos em questão se diferenciam, na direção do que propõe a autora, pela perspectiva (uma universal e outra local), e por uma disposição do conhecimento tradicional em reconhecer outras interpretações e outras abordagens como legítimas e válidas.

Apesar do contato sistemático com a sociedade envolvente, o que ocorre há mais de 200 anos, o povo Akwen percebe a relação com o conhecimento como um processo de integração com a totalidade, no sentido dado por Viveiros de Castro (2002). Os Seres humanos e não humanos estão em relação cotidiana e todas as formas de conhecer são resultado dessa interação. A cosmologia Akwen, de acordo com os trabalhos clássicos, se fundamenta no vínculo entre o que convencionamos chamar de natureza e cultura (NIMUENDAJÚ, 1942), (MAYBURY-LEWIS, 1979). A perspectiva de um continuum entre seres está sintetizada nas metades representadas por Dói e Wahirê (Sol e Lua), cofundadores e responsáveis pela existência do Povo Akwen. O huku (onça/jaguar), que os revela a existência do fogo, é um dos ancestrais mais significativos e doador de um conhecimento fundamental para a sobrevivência. É na relação com seres como estes que o povo Akwe-Xerente existe, vive e aprende. A vida social é compreendida de forma dual e ao mesmo tempo profundamente vinculada a tudo que a cerca (LÉVI-STRAUSS, 2004). A organização social é estruturada em metades compostas por clãs. A metade associada ao Sol inclui os Clãs Kuzaptedkwá (Os donos do fogo), Kbazidkwá (os donos do algodão) e Kritóidkwa (Os donos do jogo com a batata assada ou os donos da borracha). A metade Wahiré, os clãs Krozaké, Keprehi e Wahiré.

Nimuendaju descreve a relação dos Akwen com a tríade mitológica Sol, Lua e Estrela (planeta Vênus), que orientavam a vida cotidiana, marcando o tempo propício para atividades de caça e pesca, jejum e aprendizado. Os 
dias em que a lua aparecia deveriam ser dedicados à pesca, nos dias de sol à caça e nos dias da estrela todos deveriam se dedicar a ensinar e aprender. O tempo do grande jejum (dahêwakurkwa, em Akwen), era o momento em que os velhos, especialmente, se ocupavam da educação dos jovens e dos adultos do grupo, no Warã, a casa dos rapazes. Na tradição Akwen, o sentido do Warã demonstra uma concepção que claramente se opõe ao modo de fazer da educação ocidental. A palavra Warã significa, simultaneamente, a casa dos homens que ficava no centro da aldeia e o próprio espaço do centro da aldeia onde as lideranças e anciãos se reuniam para decisões importantes. Na casa dos homens, os Akwen aprendiam tudo o que precisavam para viver e ser"gente importante" (NIMUENDAJÚ, 1942).

Brito (2013) esclarece que a palavra Warã é também utilizada para lugares onde ocorre a reunião do povo Akwen, a exemplo da Praça Central da cidade de Tocantínia, onde negociam seu artesanato e onde permanecem quando precisam esperar para resolver problemas na cidade. Na praça eles se reúnem para conversar, interagir e consequentemente aprender. Giraldin e Melo (2012) citam, ainda, que o Warã é também o lugar da habitação provisória no mato, no momento em que os mais velhos estão ensinando os mais jovens a caçar, pescar e desenvolver outras habilidades de interação com o meio. Diante dessas considerações podemos sugerir que o Warã remete à sociabilidade Akwen, onde viver e educar são processos indissociáveis e acontecem no desenrolar cotidiano, além de envolver as decisões dos indivíduos e dos outros seres do ambiente que os cerca.

Aprender e conhecer, além de um processo social é uma processo intrinsecamente associado à cosmologia Akwen-Xerente. O aprendizado do fogo, por exemplo, técnica fundamental pra sobrevivência, é atribuída à onça. O conhecimento das plantas medicinais é dado aos Pajés através dos sonhos, como relata o aluno P. Xerente, do sétimo período de Pedagogia.

A Ciência para o Povo Indígena é determinada, ela vem dos antepassados. É essa ciência que nós sabemos que é repassada de pai pra filho. Antes os nossos avós acreditavam que o Sol é um Deus e todas as medicações, os remédios que são feitos. Os Pajés têm esse conhecimento, eles acreditam nisso e repassam. As raízes podem curar várias doenças, muitos têm esse saber, mas não repassam. O conhecimento vem através dos sonhos. Eles, os Pajés, 
têm sonhos e o conhecimento é aprendido. A Ciência do não Indígena para mim não tem fim. Então isso é complicado. Nós vivemos longe da cidade e não temos muito acesso pra tá acompanhando. Quando eu entrei na UFT, eu descobri que o saber aqui não tem fim, é algo que me incomoda, é muita informação. Na minha cultura eu aprendo X e o Xé sempre X. Na Universidade todos os anos as teorias mudam, as disciplinas não chegam a um consenso e na Universidade eu não consigo acompanhar. É muito conhecimento, muita informação. $\mathrm{O}$ acesso a esse conhecimento da Universidade dificulta muito pra nós. Nós ficamos muito perdidos, saímos da nossa aldeia pra buscar conhecimento, mas já estou no sétimo período de Pedagogia e não sei ao certo o que vou levar. Mesmo as pessoas que não queiram acompanhar o desenvolvimento, não podem ficar isoladas. Os jovens estão em busca do conhecimento do"Não índio"e ao mesmo tempo também as pessoas querem estudar e querem ter emprego.

Ao ser questionado sobre o impacto da universidade na vida dos jovens Xerente, ele considerou que:"Eles aprendem o que é bom, mas também pode aprender o que não é bom pra comunidade. Por exemplo, hoje todas as Aldeias têm energia elétrica e muitas casas já têm televisão". Para P. Xerente o acesso a essa gama de informações se mostra difícil por uma incoerência do saber, nas palavras do aluno: "as teorias mudam todos os anos, as disciplinas não chegam a um consenso".

V. Xerente, aluno do nono período do curso de serviço social apresenta diferenças epistemológicas fundamentais entre as perspectivas dos saberes que se "encontram" com a presença indígena na universidade:

As diferenças entre a ciência e o saber indígena estão no fato de que nosso saber está voltado pra questão de sobrevivência, questão natural, sem visar o mundo capitalista. Já aqui, o conhecimento está pra defender o capitalismo, explorar as camadas menos favorecidas. O saber indígena é um saber cultural e natural. Esse saber vem da força natural, daí que vem esse saber, por intermédio dos anciãos e dos mais velhos. Nem tudo que eles adquiriram é passado para os mais novos, pois nem tudo pode ser repassado. Segundo as explicações dos mais velhos esse saber vem através de visões, de sonhos, que aos poucos vão mostrando o conhecimento. Aí são colocados limites nesse saber, se ele pode passar, quanto tempo ele deve ficar, pra que serve, qual é a finalidade. O impacto da ciência ocidental sobre o Povo Xerente é negativo, uma vez que a "evolução" pode eliminar a vida. Já o nosso saber não interfere negativamente no ambiente, no mundo. As conseqüências negativas vão fazer as futuras gerações sofrerem com isso. Os cantos, as pinturas, toda a cultura veio da natureza, até os remédios. A linguagem científica utilizada 
na universidade é necessária, de qualquer forma precisamos nos adequar. Por outro lado, pra nós que temos outra linguagem estamos chegando de outra cultura, ela não é acessível. Mas vamos ter que procurar conhecer esse outro lado. É uma linguagem um pouco confusa, pra nós é um desafio. $\mathrm{O}$ nosso saber cultural tem seus avanços. Ele pode ter o avanço que tiver, mas nunca vai ser um avanço tão negativo quanto o da ciência moderna. Parece que a sociedade não indígena não percebe as consequências negativas que esse avanço pode ter. Já no saber tradicional indígena, quanto mais se avança, mais se preserva.

Por parte dos universitários Akwen-Xerente, percebe-se um esforço constante e uma disposição inquestionável para absorver o vocabulário científico, apesar da barreira linguística e do total desinteresse do corpo docente pela especificidade da presença desses alunos na UFT (SILVA, 2011). Eles argumentam que entender a ciência do "Não Índio" é importante para a inserção nessa sociedade e conquista de espaço e direitos. A. Xerente, aluno do quarto período de Serviço Social, percebe que a diferença entre os dois saberes é o fato de que o povo Xerente possui um saber natural:

O saber do Povo Xerente é um saber natural. O conhecimento natural em termos de plantas medicinais é um saber que a ciência não reconhecia. A saúde indígena é garantida por esse saber natural que a ciência não respeitava. É um saber natural-tradicional. Antigamente o povo tinha um conhecimento guardado na mente, não era escrito. Vi uma reportagem domingo, no fantástico, que falava que os índios da Amazônia tinham também um conhecimento oral. E eles falavam oito línguas, daí a prova de que eles são inteligentes. Mas a ciência tem reconhecido esse saber e está atrás de compreender, buscar na ciência indígena.

C. A. Xerente, aluno do quinto período de Serviço Social, afirma que há coisas boas e ruins tanto na ciência indígena como na ciência dos"Não Índios".

Com relação às ciências em si, apesar de estarmos estudando, adquirindo conhecimento, eu quero sugar o máximo possível, o que há de melhor e não o que há de pior, tanto na ciência indígena como na ciência dos"Não Indígenas".

O fato de alguns alunos indígenas se referirem ao seu conhecimento como ciência, acredito, pode manifestar a intenção de equiparar as possibilidades de conhecimento e reivindicar legitimidade para um saber cujos fundamentos são estruturados em orientações chamadas por eles de 
tradicionais, naturais e espirituais, fontes legítimas para o grupo e, portanto, merecedoras de reconhecimento.

No que se refere à história do contato dos Akwen com as formas de ensinar da sociedade envolvente, apontamos que nos primeiros aldeamentos indígenas implementados pelos religiosos católicos ainda no século XIX, já havia propostas de alfabetização dos aldeados. Na década de 1940 contavam com as aulas esporádicas oferecidas pelo Serviço de Proteção ao Índio (SPI) e na década de 1950 a atuação dos missionários batistas na cidade de Tocantínia objetivou a conversão religiosa com foco na educação escolar (GIRALDIN e MELO, 2012). Uma das intenções dos missionários batistas era traduzir os textos bíblicos para a língua Akwen a fim de evangelizá-los. Esse trabalho, em contrapartida, contribuiu para o desenvolvimento da escrita da língua. Com a criação do Tocantins, em 1988, a educação indígena foi assumida pelo estado e alguns cursos de formação para professores foram oferecidos a indígenas, o que fez com que muitos deles passassem a lecionar nas suas aldeias. O estado construiu muitas escolas na área Akwen, desconsiderando a tradição de mobilidade que os caracteriza, bem como o faccionismo clânico, marcado pela estruturação constante de novas aldeias e mudança de local. Como resultado há escolas abandonadas na área, uma vez que, construídas em tijolos, não podem ser removidas junto com as famílias. Sugerimos que da mesma maneira que o modelo físico da escola não se adéqua ao mundo Akwen ${ }^{7}$, os modelos curriculares também destoam da realidade e sentidos tradicionais.

\section{CONSIDERAÇões FinaIS}

A política educacional indígena, que segundo a lei, deve considerar a interculturalidade e a autodeterminação, ainda se caracteriza por um modelo ocidental e consequentemente colonizador, desconsiderando as percepções indígenas acerca de categorias como ensino e aprendizagem. Os Akwen percebem o aprendiz como dotado de autonomia e a aprendizagem como resultado do interesse do aprendiz e da lida cotidiana, além do que, o aprendizado pode ocorrer em múltiplos lugares, não exclusivamente na sala de aula. Outro aspecto é a atenção dedicada ao aprendizado, ouvir é um dos 
aspectos mais ressaltados na cultura, condição primordial para o processo educativo e, na direção do conceito de educação para a atenção, apresentado por Ingold (2000), sugerimos que aprender para os Akwen não é um processo com hora marcada e desprovido de sentido e interesse.

A existência de um espaço físico especial para a educação e a demarcação de tempo para que ela ocorra, sintetizados na estrutura física e na proposta da escola aos moldes ocidentais, é estranha ao mundo Akwen, uma vez que se contrapõe à lógica e às formas de pensar aprendizagem e ensino. Também se mostram estranhos os conhecimentos com os quais eles passam a lidar quando ingressam no ensino superior. Como podemos ver nas considerações apontadas pelos próprios alunos, a nossa ciência é frequentemente questionada, por vezes acusada de ser confusa, de servir a interesses "do capital", de estar alheia ao que eles chamam de saber natural. A ciência seria, nessa direção, um saber "não natural", demasiadamente marcado pela "mão humana", artificializado pela técnica. Importante afirmar que a defesa que esses alunos fazem do saber natural não deve ser interpretada como a velha e muito difundida ideia de que os Povos Indígenas vivem em "harmonia" com a natureza.

A essa ideia contrapõe-se ao fato de que a perspectiva presente nas cosmologias ameríndias não considera a cisão natureza-cultura. Natureza, portanto, não poderia ser pensada como exterior ou alheia aos seres que a habitam. Nesse sentido, consideramos como propõe Ingold (2000), que o mundo só pode ser natureza para uma existência que não habita nele. A partir dessa perspectiva o autor propõe superar epistemologicamente a dualidade natureza-cultura, uma vez que é no processo de afirmar o seu conhecimento sobre o mundo que os humanos estabelecem a separação. Considerando que o conceito de natureza denota um mundo externo esperando para receber forma e significado dado pela mente humana, o autor propõe a inviabilidade da construção a partir da proposta de um paradigma ecológico, que considere o engajamento dos seres no mundo, as formas de habitação, o "estar no mundo". A paisagem seria o horizonte de convergência entre os seres. Nela, cultura, natureza e indivíduo seriam constitutivos um do outro e suas agências deveriam ser percebidas como são, ou seja, simetricamente. 
A ideia de que a natureza é uma construção cultural é substituída pela imagem de que a ação humana está vinculada a uma continuidade entre os seres e o meio. Dessa relação surge um aprendizado que não se encontra localizado em um sujeito ou em sujeitos, mas é síntese de uma totalidade indivisível. O conceito de skillment, para o autor, reflete um aprendizado que acontece na relação com o meio, dada a condição de envolvimento e interferências mútuas entre os seres humanos e não humanos. O skillment requer uma "educação da atenção", pois não é simplesmente a reprodução de dados genéticos ou a interiorização de representações, mas um processo permanente, associado aos contextos práticos da vida, caracterizado por ser ativo, dinâmico e sistêmico. Sugerimos que é a esse processo que os alunos indígenas se referem quando fazem alusão "ao saber natural" e quando afirmam que os cantos, a cultura e até os remédios vieram da natureza. Como também o fogo, o algodão e as revelações dadas aos Pajés.

Ao se colocarem entre dois mundos e, consequentemente, entre os saberes a eles associados, os alunos Akwen Xerente da Universidade Federal do Tocantins percebem quão desvinculados da "educação para a atenção" estão os conteúdos oferecidos nos cursos que estão frequentando. Ao considerarmos a pretensão universalista, e porque não dizer arrogante, do tipo de conhecimento que pretendemos elaborar, cabe-nos apontar que muitas vezes os sentidos das leituras, do vocabulário, das avaliações, das teorias, das discussões, enfim, dos projetos pedagógicos dos cursos que oferecemos na universidade se perdem ao longo dos quatro ou cinco anos de duração. Quando P. Xerente disse que aprende o X e esse é e será sempre $X$, ele está defendendo certa objetividade do aprendizado que recebeu em casa. Por outro lado, a complexidade da lógica nativa em questão não nos permite afirmar que essa objetividade se reduz a uma predileção pelo concreto em detrimento da abstração ou da reflexão metafísica. O que essa afirmação nos sugere é que o aprendizado tradicional cumpre seu objetivo que é ensinar a viver a vida Akwen.

Por outro lado, não há na universidade em questão um movimento que indique a intenção de um diálogo com as perspectivas dos alunos que ingressam pelo sistema de ação afirmativa. As possibilidades dadas pela 
presença indígena no ambiente acadêmico são ignoradas, uma vez que não houve um processo de reflexão e preparação para recebê-los. Toda a tradição a qual pertencem, as formas de abordar o meio em que vivem, de elaborar sentidos para os fenômenos que os cercam e suas estruturas de aprendizado são desconsiderados no ambiente acadêmico. Dessa forma seus saberes permanecem silenciados, assim como sua presença, muitas vezes invisibilizada e até mesmo rejeitada. Uma universidade em que seus agentes acreditam que "só tem a ensinar", permanece colonizadora. Por isso, a criação de mecanismos de diálogo que reconheçam outras epistemologias, possibilitaria ampliar as próprias perspectivas da universidade e, sem dúvida, a fariam avançar, tanto no acolhimento real à diversidade representada pelos alunos indígenas, como na produção de conhecimentos que contribuam para a promoção e valorização dos seus saberes.

\section{BETWEEN WORLDS AND BETWEEN KNOWLEDGES: EPISTEMOLOGICAL CHALLENGES OF AKWEN-XERENTE STUDENTS AT THE FEDERAL UNIVERSITY OF TOCANTINS.}

ABSTRACT: As a part of the results in a 2011 research addressing indigenous students of the Federal University of Tocantins (UFT), we present a few reflections on how these Akwen-Xerente people, studying at Miracema Campus of UFT, perceive the knowledge they deal with after joining the academy, how they compare it with the knowledge of their own society, called by them "traditional and natural", and yet how they critically escape of the scientificism that still persists in several departments of the academy. Considering the characteristic elements of Akwen ways of seeing and interpreting the world, we also question the lack of openness by the University to the epistemological tradition they represent.

KeYwords: Akwen-Xerente indigenous students. Academic knowledge. Traditional knowledges.

\section{ENTRE MUNDOS Y ENTRE SABERES: DESAFÍOS EPISTEMO-LÓGICOS DE LOS ESTUDIANTES AKWEN XERENTE DE LA UNIVERSIDAD FEDERAL DE TOCANTINS}

RESUMEN: Como parte de los resultados de una investigación realizada con estudiantes indígenas de la Universidad Federal de Tocantins (UFT) en 2011, se presentan en este artículo algunas reflexiones sobre cómo los estudiantes Akwen-Xerente, matriculados 
en la UFT, del campus de Miracema, ven los conocimientos con los cuales pasan a enfrentar al ingresar en la universidad. Presentamos también como los comparan al saber de su sociedad, por ellos denominado "tradicional y natural", y como escapan críticamente al cientificismo todavía persistente en muchos sectores de la academia. Teniendo en vista elementos característicos de las maneras Akwen de ver e interpretar el mundo, ponemos en duda la falta de apertura de la universidad para la tradición epistemológica por ellos representada.

Palabras clave: Alumnos indígenas Akwen Xerente. Conocimiento académico. Saberes tradicionales.

\section{NOTAS}

1) O reconhecimento do direito originário dos indígenas brasileiros aos territórios tradicionalmente ocupados, bem como à sua cultura e identidade, legitima o uso do termo Povos Indígenas, de direito anterior à constituição do atual estado brasileiro.

2) $O$ primeiro nome se refere à autodenominação dos povos citados, seguido pelo nome que lhes foi atribuído na relação com a sociedade envolvente.

3) Há famílias Guarani Mbyá vivendo na Terra Indígena Xambioá, na região do Baixo Araguaia,TO. Como explica Nascimento (2013, p. 85), a presença Guarani contribuiu para "o restabelecimento quantitativo do Povo Karajá Xambioá", drasticamente reduzido em função dos processos de violência, marcados pelas tentativas de extermínio físico e cultural, comuns à história dos povos indígenas brasileiros.

4) O levantamento que apresentamos foi realizado através de uma pesquisa nos sete campi da UFT, no ano de 2011, a fim de identificar os alunos Akwen Xerente matriculados.

5) Dois restaurantes universitários foram inaugurados na UFT, em 2014. Um no campus de Palmas e outro no campus de Araguaína. Os alunos indígenas são isentos do pagamento pelas refeições.

6) Lévi-Strauss e Evans-Pritchard sustentam a tese de que abordagens científicas sobre o universo e a natureza, elaboradas por povos não ocidentais, operam dentro da mesma lógica da ciência moderna, como mostra Cunha (2007, p.79): "sobre isso, os antropólogos Evans-Pritchard, no final dos anos 30 do século passado, e Claude Lévi-Strauss, no início dos anos 60, deram respostas incisivas. Não há lógicas diferentes, mostrou Evans-Pritchard com seu estudo sobre a bruxaria e oráculos entre os Azandes do Sudão, o que há são premissas diferentes sobre o que existe no mundo. Dada uma ontologia e protocolos de verificação, o sistema é de uma lógica impecável a nossos olhos. Quanto a Lévi-Strauss, ele também afirma, em seu livro $O$ 
Pensamento Selvagem, de 1962, que saber tradicional e conhecimento científico repousam ambos sobre as mesmas operações lógicas e, mais, respondem ao mesmo apetite de saber. A ciência moderna hegemônica usa conceitos, a ciência tradicional usa percepções. É a lógica do conceito em contraste com a lógica das qualidades sensíveis. Enquanto a primeira levou a grandes conquistas tecnológicas e científicas, a lógica das percepções, do sensível, também levou, afirma Lévi-Strauss, a descobertas e invenções notáveis e a associações cujo fundamento ainda talvez não entendamos completamente. Lévi-Strauss, portanto, sem nunca negar o sucesso da ciência ocidental, sugere que esse outro tipo de ciência, a tradicional, seja capaz de perceber e como que antecipar descobertas da ciência tout court".

7) A presença física da escola representa o processo dialético que está associado à vida Akwen na relação com a sociedade envolvente. Ao mesmo tempo em que a construção de escolas é uma reivindicação de todo o povo, assim como saúde, saneamento e assistência técnica para o plantio de roças, há muitas críticas ao que ela representa no contexto em questão. Neste sentido, constatamos que ao mesmo tempo em que reivindicam a construção de mais escolas, podem abandoná-las quando consideram a necessidade de mudar de aldeia ou área dentro da Terra Indígena (TI). Segundo E. Xerente, liderança indígena, há cerca de trinta escolas aban-

donadas dentro da $\mathrm{TI}$, o que é resultado, tanto da demissão recente de professores, como das mudanças de aldeia, muito comuns para os Akwen.

\section{REFERÊNCIAS}

BRASIL. Constituição (1988). Constituição da República Federativa do Brasil. Brasília, DF: Senado, 1988.

BRITO, V. O Jovem Akwe e o mercado de trabalho. Trabalho de Conclusão de curso (Graduação Serviço Social) - Universidade Federal do Tocantins, Miracema, TO, 2013.

CARVALHO, D. A. A política de cotas da Universidade Federal do Tocantins: Concepção e implicações para a permanência dos estudantes indígenas. Dissertação (Mestrado em Educação Brasileira) - Faculdade de Educação da Universidade Federal de Goiás, Goiânia, GO, 2010.

CUNHA, M. C. Relações e dissensões entre saberes tradicionais e saber científico. Revista USP, São Paulo, n. 75, p. 76-84, set./nov. 2007.

Cultura com aspas e outros ensaios. São Paulo: Cosac Naify, 2009.

EVANS-PRITCHARD, E. E. Bruxaria, oráculos e magia entre os Azande. Rio de Janeiro: Jorge Zahar Ed, 2005.

GIRALDIN, O; MELO, V.M.C. Os Akwe-Xerente e a busca pela domesticação da escola. Revista Tellus, Campo Grande, n. 22, p. 177-199, jan/jun.2012. 
IBGE. Censo demográfico 2010. Disponível em: <www.ibge.gov.br>. Acesso em: 20 out. 2015.

INGOLD, T. The perception of the environment: essays in livelihood. London: Routledge, 2000.

LÉVI-STRAUSS, C. O pensamento selvagem. 8. ed. Campinas: Papirus, 1989.

MAYBURY-LEWIS, D. Dialectical societies: the Gê and Bororo of Central Brazil. Cambridge: Harvard University Press, 1979.

. O Selvagem e o Inocente. Campinas: Ed. Da Unicamp, 1990.

MELATTI, J.C. A situação dos craôs na área pastoril do Tocantins. Rio de Janeiro: UFRJ, 1967.

NASCIMENTO, A. M. Ações para a revitalização linguístico-cultural entre o povo

Xambioá: lições desde projetos comunitários. Revista Tellus, Campo Grande, n.25, p.83-105, jul./dez. 2013.

NIMUENDAJÚ, C. The Serente. Los Angeles: The Southwest Museum, 1942.

RAMOS, A. R. O pluralismo brasileiro na berlinda. Série Antropologia, Brasília, n. 353, p. 1-17, jan/dez. 2004.

. O índio hiper-real. Revista Brasileira de Ciências Sociais, São Paulo, n.10. p. 5-14, jan/dez. 1995.

RIBEIRO, D. Os índios e a civilização: a integração das populações indígenas no Brasil moderno. São Paulo: Companhia das Letras, 2005.

SILVA, R.P. O índio negado e o índio desejado: a pacificação dos indígenas na construção da identidade do Tocantins. Revista Tellus, Campo Grande, n.19, p. 145-162, jul./dez.2010

Pesquisa sobre a presença indígena na UFT. Palmas: UFT, Grupo de Trabalho Indígena, 2011.

The Indians Who never slept: "The Indigenous from Tocantins (North Of Brazil) and the Protests of June." Fieldsights - Hot Spots, Cultural Anthropology Online, December 20, 2013. Disponível em: <http://www.culanth.org/fieldsights/445-the-indians-who-never-slept-the-indigenous-from-tocantins-north-of-brazil-and-the-protests-of-june>. Acesso em: 22 out. 2015.

UNIVERSIDADE FEDERAL DO TOCANTINS. Relatório de avaliação institucional 2012. UFT: Palmas, 2013. Disponível em: <http://download.uft.edu.br/?d=62494bce-8b38439e-8521-be6b28080fcf;1.0>. Acesso em: 22 out. 2015.

VIVEIROS DE CASTRO, E. B. A inconstância da alma selvagem e outros ensaios de Antropologia. São Paulo: Cosac \& Naify, 2002. 
REIJANE PINHEIRO DA SILVA: Doutora em Antropologia pela Universidade Federal do Rio Grande do Sul (UFRGS). Atualmente é professora adjunta da Universidade Federal do Tocantins (UFT). Possui experiência na área de antropologia e sociologia, com ênfase em Cultura e identidade regional, atuando principalmente nos seguintes temas: universo country, identidade regional e imaginário.

E-mail: reipinheiro@smail.com 